\title{
Retraction Note: Application of land ecological environment risk assessment based on SAR image
}

\author{
Wenguang $\mathrm{Ji}^{1}$ · Juanmin Cui ${ }^{1}$
}

Published online: 9 December 2021

(c) Saudi Society for Geosciences 2021

Retraction Note: Arabian Journal of Geosciences (2021) 14: 1713

https://doi.org/10.1007/s12517-021-07951-1

The Editor-in-Chief and the Publisher have retracted this article because the content of this article is nonsensical. The peer review process was not carried out in accordance with the Publisher's peer review policy. Author Wenguang Ji has not responded to correspondence regarding this retraction. The Publisher has not been able to obtain a current email address for author Juanmin Cui.

The original article can be found online at https://doi.org/10.1007/ s12517-021-07951-1.

Wenguang Ji

jiwenguanghb@163.com

1 Hebei Normal University for Nationalities, Chengde 067000,

Hebei, China 